\title{
LEARNING BY DOING IN A MULTI-PRODUCT MANUFACTURING ENVIRONMENT: PRODUCT VARIETY, CUSTOMIZATIONS, AND OVERLAPPING PRODUCT GENERATIONS
}

\author{
Carolyn D. Egelman \\ Dennis Epple \\ Linda Argote \\ Erica R.H. Fuchs \\ Working Paper 19674 \\ http://www.nber.org/papers/w19674 \\ NATIONAL BUREAU OF ECONOMIC RESEARCH \\ 1050 Massachusetts Avenue \\ Cambridge, MA 02138 \\ November 2013
}

The authors gratefully acknowledge the financial support provided by Science of Science and Innovation Policy \& Innovation and Organization Sciences Joint NSF Grant 0965442, Innovation \& Organization Sciences NSF Grant 0622863, a Sloan Industry Studies Grant, and a Berkman Faculty Development Grant. The authors also gratefully acknowledge the support from managers, engineers, and employees at the study's focus firm. The views expressed herein are those of the authors and do not necessarily reflect the views of the National Bureau of Economic Research.

NBER working papers are circulated for discussion and comment purposes. They have not been peerreviewed or been subject to the review by the NBER Board of Directors that accompanies official NBER publications.

(C) 2013 by Carolyn D. Egelman, Dennis Epple, Linda Argote, and Erica R.H. Fuchs. All rights reserved. Short sections of text, not to exceed two paragraphs, may be quoted without explicit permission provided that full credit, including $\odot$ notice, is given to the source. 
Learning by Doing in a Multi-Product Manufacturing Environment: Product Variety, Customizations, and Overlapping Product Generations

Carolyn D. Egelman, Dennis Epple, Linda Argote, and Erica R.H. Fuchs

NBER Working Paper No. 19674

November 2013

JEL No. D2,L2,L6,O3

\begin{abstract}
Extending research on organizational learning to multi-product environments is of particular importance given that the vast majority of products are manufactured in such environments. We investigate learning in a multi-product facility drawing on exceptionally rich data for a manufacturing firm that is a leading producer of high technology components. Weekly data for 10 years from the firm's production and human resource tracking systems are augmented by surveys of managers and engineers and by extensive first-hand observation. We find that productivity improves when multiple generations of the firm's primary product family are produced concurrently, reflecting the firm's ability to augment and transfer knowledge from older to newer product generations. No significant transfer of knowledge is evident between the primary product family and other products. Productivity is, however, decreased when the production facility is faced with extensive within-product buyer-specific customizations. We develop the implications of these findings for theory and practice.
\end{abstract}

Carolyn D. Egelman

Dept. of Engineering \& Public Policy

Carnegie Mellon University

Baker Hall 129

Pittsburgh, PA 15213

cdenomme@cmu.edu

Dennis Epple

Tepper School of Business

Carnegie Mellon University

Posner Hall, Room 257B

Pittsburgh, PA 15213

and NBER

epple@cmu.edu
Linda Argote

Tepper School of Business

Carnegie Mellon University

Pittsburgh, PA 15213

argote@andrew.cmu.edu

Erica R.H. Fuchs

Dept. of Engineering \& Public Policy

Carnegie Mellon University

Baker Hall 131E

Pittsburgh, PA 15213

erhf@andrew.cmu.edu 


\section{Introduction}

Organizational learning and knowledge transfer are key to any firm's competitive advantage [Kogut and Zander (1992), Argote and Ingram (2000)]. Yet, learning and knowledge transfer in a multi-product production setting are not well understood. The production and operations management literature largely starts from the understanding that production of a variety of products is harmful. At the same time the organizational learning literature suggests that there can be benefits to producing heterogeneous products. These differences in findings with respect to product heterogeneity can, to some extent, be traced to differences in the nature of such heterogeneity. In this paper we leverage facility-level production data to unpack the nature of product heterogeneity in that facility, and the implications of that heterogeneity for organizational learning and knowledge transfer.

This work investigates organizational learning and knowledge transfer in a U.S.-owned overseas manufacturing facility that is a leading producer of high technology hardware components. The firm produces five generations of high-volume focus products as well as several non-focus products that vary widely from the focus products in form factor and market application and are produced in relatively small volumes. The firm also undertakes thousands of variations of products to meet individual buyer specifications. We draw on 10 years of firm archival data, along with qualitative survey and observational data collected at the site, to develop insights into the acquisition and transfer of knowledge within and across product generations. Our analysis employs weekly data on five generations of a focus product, including the thousands of variations tailored to buyer specifications, as well as data for the suite of heterogeneous small-volume products produced by the firm. These data coupled with information from surveys and interviews with managers, engineers, and trainers enable us to understand the differential effects on knowledge acquisition and transfer of contemporaneous variation in product types as well as intertemporal variation as technological advances bring new products into the firm's repertoire.

Our results reconcile differences between the organizational learning and production and operations management literatures by identifying both advantages and disadvantages to product heterogeneity on the production line, depending on the extent and nature of

product differences. We find that productivity improves when multiple generations of the same product are produced in the same facility. This positive impact on productivity of having multiple generations of the same product on the line is explained in part by the 
firm's ability to transfer knowledge rapidly from older to newer generations of the product and thereby improve long-term productivity. In contrast, we find productivity is decreased both when the production line is faced with product types that are quite different from each other and when faced with increases in buyer-specific product variations. In addition, we do not find evidence of knowledge depreciation.

\section{Theoretical Motivation}

\subsection{Organizational Learning}

Learning curves have been found within many organizations and serve as a valuable indicator of the extent to which organizational performance improves with experience [Lapré and Nembhard (2010), Argote et al. (2003)]. Learning has been found in a breadth of industries from service industries, such as pizza franchises and booksellers [Darr et al. (1995), Ton and Huckman (2008)], to a variety of manufacturing settings, such as semiconductors, airplanes, ships, and trucks [Argote et al. (1990), Epple et al. (1991), Benkard (2000)].

The classic form of this organizational learning curve is given as

$$
y_{i}=a Q_{i}^{b}
$$

and is often written for estimation purposes in logarithmic form

$$
\ln y_{i}=c+b \ln Q_{i}
$$

where $y$ is the unit cost or number of labor hours to produce the $i$ th unit, $a$ is cost or the number of labor hours required to produce the first unit, $c$ is a constant equal to $\ln a, Q$ is the cumulative number of units through time period $i, b$ is the learning rate, and $i$ is a time subscript [Argote (2013)]. In addition to unit costs, other metrics such as defects per unit or waste per unit [Lapré et al. (2000)] have been shown to follow a learning curve pattern. Thus, $y$ can represent different performance metrics that vary, and generally improve, with experience.

From the learning rate, a progress ratio can be calculated. Typically the progress ratio, $p$, is the change in the performance metric, $y$, when cumulative production is doubled or, mathematically, $p=2^{b}$ [Dutton and Thomas (1984)]. Dutton and Thomas performed an assessment across more than 200 empirical studies of progress functions and found that learning rates differ widely not only across different industries, processes, and products but also within the same or similar processes and products [Dutton and Thomas (1984)]. 
This has stimulated research focused on determining reasons for this variation in learning rates.

The accumulated learning within a firm is often called organizational knowledge. Knowledge within a firm can be embedded in its people, its products, its technology, or its structure [Walsh and Ungson (1991)]. The ability of a firm to transfer knowledge effectively across these elements within its own organizational boundaries can be a key element of competitive advantage [Argote (2013), Argote and Ingram (2000)]. Past research has quantified the amount of knowledge transfer across boundaries in the case of ship production (cross-location transfer), truck production (cross-shift transfer), and aircraft production (cross-product transfer) by modifying the experience term in the classic learning model to include a transfer parameter [Argote et al. (1990), Epple et al. (1996), Benkard (2000)].

\subsection{Learning Across Products}

The majority of organizational learning studies focus on production of a small number of products with minor variations (e.g. aircraft, ships, trucks, and automobiles) [Alchian (1963), Rapping (1965), Argote and Epple (1990), Levitt et al. (2013)]. Yet, 87\% of U.S. output comes from multi-product firms and over half of all U.S. firms alter their product mix every five years [Bernard et al. (2010)]. Research that looks at learning and product heterogeneity shows both advantages and disadvantages to an increase or change in product variety. A consensus has not emerged as to when and how firms should handle processing a multitude of products simultaneously.

The benefits associated with specialization were noted as early as Adam Smith [Smith (1776)]. Indeed, production management and operations largely starts from the assumption that product variety increases production costs. Results from this literature show that changeovers in a multi-product environment can be costly due to operators forgetting in the time in between working on same products [Shtub et al. (1993)] and in the time to switch tools or molds [Womack et al. (1990)]. An increase in the variety of products produced on one line also complicates task scheduling, planning of material handling and inventory, as well as quality control [Fisher and Ittner (1999)].

Studies have shown different ways to mitigate the negative impacts of product heterogeneity. Designing products with shared components [Fisher et al. (1999)], products that have commonality in their design [Desai et al. (2001)], or products that implement a mod-

ular design or have components that can be reused [Suarez et al. (1995)] can all improve 
productivity on a production line that handles a mixture of products. Lean manufacturing and flexible manufacturing systems also implement methods to allow a production line to handle a variety of products efficiently [Suarez et al. (1996), MacDuffie et al. (1996), Gaimon and Morton (2005), Suarez et al. (1995), Randall and Ulrich (2001)]. Goyal and Netessine investigate differences between product flexibility and volume flexibility in the context of response to demand uncertainty and find adding volume flexibility to existing product flexibility is always beneficial but that the converse is not always true [Goyal and Netessine (2011)]. An analysis of survey data of automotive manufacturing plants spanning from 1999-2007 by Gopal et al. found that the high costs of new product introductions could be reduced by launching new products at flexible plants with experience in related platforms [Gopal et al. (2013)]. Studies on these flexible systems characterize the different types of flexibility these systems can handle yet do not address long term implications for learning or knowledge development that arise from these product differences.

Despite this focus in the production and operations management literature on mitigating product variety and the harmful implications thereof, not all empirical studies find a negative impact from an increase in product heterogeneity. Indeed, the literature on organizational learning suggests that the impact of product heterogeneity can be positive. Past work on accidents in the airline industry suggest that organizations learn more from diverse than homogenous experiences [Haunschild and Sullivan (2002)]. In manufacturing, Bernard et al. (2010) show that changing product heterogeneity causes firms to reallocate resources more efficiently. Additionally, Wiersma (2007) found that heterogeneity in related products had a positive impact on the learning rate within the Royal Dutch Mail. Boh et al. (2007) found that heterogeneous experience in related systems enhanced learning in software development teams.

Recent work has begun to unpack why product variety can in some cases have positive implications and in other cases negative implications for productivity. Work by Staats and Gino (2011) on the Japanese banking industry found the impact of variety on worker productivity to differ depending on whether a worker experienced the variety within a single day or across several days. Specialization of tasks within a single day increased worker productivity. However, variety (switching tasks) over the course of multiple days improved productivity of the same workers. In addition, workers who experienced higher variety stayed longer at the firm than those experiencing lower variety. Other work has 
suggested that heterogeneity within certain confines can be valuable for a worker's ability to learn. An experimental study performed by Shilling et al. found that learning rates were faster when participants were given related tasks than when participants were given identical tasks or completely unrelated tasks [Schilling et al. (2003)].

The effect of product variety on productivity also depends on the ability of firms to transfer knowledge between or across products. Utilizing a dataset that includes successive models of airplanes built simultaneously on the same production line, Benkard (2000) finds that there are substantial spillovers from one model to another. Studying the introduction of three successive variants of an automobile, Levitt et al. (2013) obtain mixed results. The researchers find that defect rates of the first model were adversely impacted by the ramp up of the second model while defect rates for the second were not impacted by ramp up of the third. In the case of knowledge transfer across DRAM generations Irwin and Klenow (1994) find transfer is statistically significant in five of seven generations and economically significant (producing a non-trivial impact of production experience) in two of those generations.

Retention of knowledge is another factor influencing learning. Beginning with Argote et al. (1990), a series of studies investigated whether organizational knowledge is cumulative, as the conventional learning curve implies, or whether knowledge depreciates. Researchers found variation in the extent of knowledge depreciation with several studies finding significant depreciation [Benkard (2000), Darr et al. (1995), David and Brachet (2011), Kellogg (2011), Kim and Seo (2009), Madsen and Desai (2010)] and other studies finding little or no depreciation [Ingram and Simons (2002), Thompson (2007)]. Understanding how the extent of knowledge depreciation varies as a function of the organizational context [Argote (2013)] and the mechanisms underlying depreciation [David and Brachet (2011)] are active research areas. Knowledge retention, transfer and product variety can be related so it is important to examine them together in a study. For example, product variety can cause negative transfer when workers inappropriately apply knowledge garnered on one product to another. If not controlled for, this negative transfer could cause the appearance of incomplete knowledge retention.

Past research in operations management and organizational behavior raises important questions regarding how the nature of product variety might influence organizational learning and knowledge transfer. We bring empirical evidence to the debate about whether product variety is harmful or helpful by examining the effects of different types of heterogeneity 
and the mechanisms through which the effects occur in a multi-product manufacturing environment.

\subsection{Research Questions}

Our research addresses several interrelated questions all of which focus on bringing understanding of learning and knowledge transfer into a multi-product manufacturing environment:

1. Does organizational learning occur in a multi-product environment?

2. Does product heterogeneity affect productivity and learning from experience?

3. Does knowledge transfer occur across products?

4. Does knowledge transfer explain the effect of product heterogeneity on productivity and organizational learning?

5. Does knowledge acquired through organizational learning depreciate?

In order to unpack the effect of product heterogeneity, we develop measures of different types of heterogeneity and investigate their effects on both short-term and long-term productivity by analyzing the effect of product heterogeneity on the firm's knowledge base.

\subsection{Definitions and Measures of Product Variety}

Product variety can exist on many levels within a factory or firm, and studies within the production and operations management literature use many definitions of product variety. How product mix is defined and measured can affect its impact on productivity. Indeed, MacDuffie et al. find in a study of the automotive industry that different forms of product variety (e.g., model mix complexity, parts complexity, option content, and option variability) have varied impacts on plant productivity [MacDuffie et al. (1996)]. In the printed circuit board industry, Suarez et al. (1995) identify predictors of flexibility but do not find a relationship between flexibility and product cost or quality. In the case of the bicycle industry, work examines variation across attributes (e.g., material, geometry and size, and color) of components and finds that some variations increase production costs, while others instead impact "market mediation" costs (i.e., uncertainty in product demand) [Randall and Ulrich (2001)]. Finally, Kekre and Srinivasan (1990) examine product line breadth based on self-reported survey data from the PIMS (Profit Impact of Marketing Strategies) database in their analysis of over 1,400 business units (most of which are part of a Fortune 500 firm) and find firms with larger product lines have increased market share with minimal impact on production costs. Although these studies have advanced our understanding 
of the effects of product variety on various measures of plant performance, they have not examined the long-term implications of product variety for organizational learning and the development of a firm's knowledge stock. We aim to fill this gap by analyzing the effect of product variety on both productivity in the short run and learning in the long run leveraging detailed plant-level data.

\section{Data and Methods}

We analyze organizational learning and knowledge transfer within a firm that is a leading producer of high technology hardware components and one of the leading revenue earners in its industry. The firm, which is U.S. owned, began moving production from the U.S. to a developing country in 2001 and by 2004 all of the products had been transferred to the production facility in the developing country. Our analysis draws on data from 2001 to 2011 at the manufacturing facility in the developing country. The setting we study has characteristics that make it exceptionally well suited to researching learning in a multiproduct environment: high technology products that require sophisticated assembly and testing, multiple generations of focal products, large numbers of customized variations within generations, and a suite of market-related but physically quite different non-focus products.

\subsection{Data Collection}

Our paper leverages three types of data: 1) quantitative archival data from the firm's production and human resource tracking systems, 2) surveys conducted with engineers and direct line worker trainers about process differences, and 3) a qualitative understanding of production floor and firm operations based on on-site semi-structured interviews and participant observations at the facility. Table 1 details the types of data collected on the site visits. Over its history the factory has kept detailed records of production volumes and yields, sales orders and shipments, labor hours worked, and employment histories of all its employees. From this record, the data we have obtained, spanning almost a decade, provide extraordinary detail, including order date, requested delivery date, actual delivery date, and detailed specifications for each of millions of units produced. In addition, we have obtained weekly data on labor inputs, and detailed measures of process steps required

for each product type as well as assessments by engineers and trainers of the relative complexity of these process steps. Our research has also benefitted from knowledge obtained 
Table 1 Overview of data collection.

\begin{tabular}{|c|c|}
\hline \multicolumn{2}{|c|}{ Site Visit \& Data Collection Overview } \\
\hline Preliminary Site Visit & 2 days \\
\hline First Data Collection Collection Site Visit & 7 days \\
\hline Second Data Collection Site Visit & 10 days \\
\hline Production Floor Observation & $\begin{array}{l}12 \text { hours observation } \\
2 \text { hours participation }\end{array}$ \\
\hline Semi-structured Interviews & $\begin{array}{c}8 \text { with vice president } \\
30 \text { with engineers \& managers } \\
3 \text { with trainers } \\
\end{array}$ \\
\hline Surveys & $\begin{array}{c}11 \text { final product engineers } \\
2 \text { subcomponent engineers } \\
3 \text { trainers } \\
\end{array}$ \\
\hline Field Notes & 112 typed pages \\
\hline Archival Data Records & $\begin{array}{c}\text { 17.5GB of data from production } \\
\text { and human resources databases } \\
\text { from as early as } 2001\end{array}$ \\
\hline
\end{tabular}

by extensive observation within the facility and from exceptional support and expertise of the company's management, engineers, and trainers.

3.1.1. Quantitative Archival Data Details about each type of data provided by the firm for this study are given in Table 2.

We use the company's weekly shipment data from 2001-2011 as our measure of weekly firm output $\left(q_{t}\right)$, and cumulative output, or production experience $\left(Q_{t}\right)$. The sales and shipment tracking database, from which we retrieved these data, tracks details of all orders the factory receives, manufactures, and ships, and includes data on these dates and order volumes. In addition, the shipment data include information on when orders were placed, requested for delivery, scheduled for shipment, and actually shipped.

Although shipment data can have limitations as a measure of output, due to a potential lag between completion of production and shipment to the customer, these limitations are not an issue in our empirical context. Because of distinctive specifications from customers, the firm produces almost entirely to order. Hence, inventory holdings are minimal, and production-delivery lags are short. As long as any order-delivery lags vary randomly from week to week, these variations do not bias our estimates [Greene (2003)]. Systematic variation in order-delivery lags could potentially cause bias, for example, if end-of-quarter reports incentivized shortening such lags as the end of quarter draws near. To investigate this possibility, we have included within-quarter variables denoting the number of weeks 
Table 2 Overview of quantitative archival data sources.

\begin{tabular}{|c|c|c|c|c|}
\hline \multirow[b]{2}{*}{ Data Source } & \multicolumn{2}{|c|}{ Primary Data } & \multicolumn{2}{|c|}{ Secondary Data } \\
\hline & $\begin{array}{c}\text { Sales \& Shipment } \\
\text { Reports }\end{array}$ & $\begin{array}{c}\text { Human Resources } \\
\text { Employment } \\
\text { Database }\end{array}$ & $\begin{array}{l}\text { Production Floor } \\
\text { Tracking System }\end{array}$ & $\begin{array}{c}\text { Hard Copies of } \\
\text { Weekly Hours } \\
\text { Report }\end{array}$ \\
\hline Data Details & $\begin{array}{l}\text { Volume of each } \\
\text { order and date } \\
\text { the order was } \\
\text { place, requested, } \\
\text { scheduled for } \\
\text { shipment, and } \\
\text { actually shipped }\end{array}$ & $\begin{array}{l}\text { Date that each of } \\
\text { the factory's over } \\
20,000 \text { employees } \\
\text { was hired, } \\
\text { resigned, } \\
\text { promoted, or } \\
\text { changed } \\
\text { shifts/supervisors }\end{array}$ & $\begin{array}{l}\text { Input and output } \\
\text { production } \\
\text { volumes for key } \\
\text { testing steps } \\
\text { broken down by: } \\
\text { shift, product, } \\
\text { exact test station, } \\
\text { and operator }\end{array}$ & $\begin{array}{l}\text { Weekly hours } \\
\text { worked by rate } \\
\text { and division }\end{array}$ \\
\hline $\begin{array}{l}\text { Data } \\
\text { Availability }\end{array}$ & $2001-2011$ & $2001-2011$ & $2004-2009$ & $2004-2008$ \\
\hline $\begin{array}{l}\text { Calculated } \\
\text { Variable(s) }\end{array}$ & $\begin{array}{c}\text { Shipment volumes } \\
\left(q_{t}, Q_{t}\right), \text { Product } \\
\text { heterogeneity }\left(s_{n, t},\right. \\
\left.G_{t}, M_{t}\right) \text {, Order } \\
\text { equivalents of } \\
\text { product } \\
\text { heterogeneity } \\
\text { measures for } \\
\text { instruments }\end{array}$ & Labor input $\left(L_{t}\right)$ & $\begin{array}{c}\text { Per-step } \\
\text { production volumes }\end{array}$ & Labor hours \\
\hline
\end{tabular}

to the end of quarter. As we discuss more fully below, these variables do not affect our findings.

We use the company's weekly employed count of direct line workers from 2001-2011 as a measure of labor input $\left(L_{t}\right)$. The employment database, from which we retrieve these data, tracks each employee's hire date, resignation date, and any promotions or changes in position at a daily level. Employee counts can, nonetheless, have limitations as a measure of labor input if employees do not work regularly. Our firm experienced growing demand over the time period we study, and local labor conditions permitted the firm to add to its workforce as needed to accommodate growing demand. Hence, the count of employees and actual labor input track each other closely.

3.1.2. Surveys/Structured Interviews We worked with the firm's engineers to establish a list of process steps for each of the focus products. The aggregate of these lists encompassed seventy-seven different processes across the focus products. Once the process list was defined, we distributed surveys to additional engineers, asking them: to rank process difficulty by product; estimate the commonality of machinery, trainers, technicians, and engineers across focus products; and answer general questions about commonalities across 
products. These questions included eliciting the engineer's perceptions of what makes products similar and their experience with implementing new products on the production line.

The processes cover three stages of production: assembly, testing, and final preparation. Different engineers are responsible for each of these stages of production. A total of eleven engineers in the primary section of the factory filled out the survey from which we develop our engineering process measures. Two additional engineers filled out the survey for sections of the factory responsible for producing subcomponents. A sample of the survey given to engineers can be found in Appendix A.

We also used a modified version of the process survey to conduct structured interviews with three trainers. The modified survey can be found in Appendix B. We talked through each process step with the trainer and asked for a process categorization and average training time for each process. One head trainer is responsible for the three stages of production within the primary production line. While we interviewed two other trainers responsible for sections of the facility that produce subcomponents, we relied on our detailed interview with the head trainer for creating the training process measures used in our analysis.

3.1.3. Qualitative Data Over the course of the three site visits, we spent a total of nineteen days in the production facility, twelve hours observing the production floor, and an additional two hours actually participating on the production line (assisted by a trainer). We performed forty-one semi-structured interviews with managers, engineers, and trainers. These observations and interviews were transcribed, along with regular interactions with employees throughout the day, observations from a weekend outing spent with two employees, and interactions over the course of twenty-four meals shared with employees, into 112 typed pages of notes. All transcriptions were completed within at least forty-eight hours, the majority within twenty-four hours. Through these interactions we were able to gain insights in to the history of the plant, how engineers and managers think about

product similarity, and how production innovations, such as altered training procedures or new testing equipment, are incorporated into the flow of the plant.

\subsection{Product Heterogeneity}

Between 2001 and 2011, the developing country facility manufactured five types of focus products and fourteen types of non-focus products, comprising $86 \%$ and $14 \%$, respectively, of total production volume. Table 3 details for each of the focus and non-focus product 
Table 3 Comparison of focus and non-focus products.

\begin{tabular}{llccc}
\hline $\begin{array}{l}\text { Focus or } \\
\text { Non-Focus } \\
\text { Products }\end{array}$ & Form Factor & $\begin{array}{c}\text { Percentage of } \\
\text { Cumulative } \\
\text { Shipped Volume }\end{array}$ & $\begin{array}{c}\text { Number of } \\
\text { Distinct } \\
\text { Part Numbers }\end{array}$ & $\begin{array}{c}\text { Physical Volume } \\
\text { Relative to } \\
\text { Focus FF1 }\end{array}$ \\
\hline \hline Focus & FF1: Focus Products 1-2 & $72.83 \%$ & 887 & 1.0 \\
& FF2: Focus Products 3-5 & $12.91 \%$ & 252 & 1.0 \\
\hline Non-focus & Focus Variation 1 & $3.16 \%$ & 2,227 & 1.0 \\
& Focus Variation 2 & $1.95 \%$ & 127 & 1.2 \\
& Focus Variation 3 & $0.16 \%$ & 11 & 1.0 \\
& Subcomponent & $2.03 \%$ & 109 & 0.1 \\
& Accessory & $1.87 \%$ & 5 & 1.1 \\
& Non Focus 1 & $1.79 \%$ & 385 & 3.1 \\
& Non Focus 2 & $1.55 \%$ & 1.862 & 6.7 \\
Non Focus 3 & $0.73 \%$ & 51 & 8.2 \\
Non Focus 4 & $0.11 \%$ & 14 & 1.3 \\
Non Focus 5 & $0.10 \%$ & 14 & 9.0 \\
Non Focus 6 & $0.05 \%$ & 157 & 5.5 \\
Non Focus 7 & $0.02 \%$ & 17 & 0.5 \\
Non Focus 8 & $0.01 \%$ & 25 & - \\
\hline Miscellaneous & $0.72 \%$ & 977 & \\
\hline
\end{tabular}

types: the shipment volumes as a percentage of cumulative shipped volume, number of distinct part numbers (a measure of variety within specific product types driven largely by customer-specific customizations), and physical volume relative to the primary focus product form factor.

The focus products are similar in form factor (i.e., size and shape) and end use. While the end use of focal products does not change across generations, technological advances result in changes of components within those products from one generation to the next, and associated increase in capabilities. Each new generation of the focal product adds to the firm's product offerings; prior generations continue to be produced and sold. The firm considers these focal products its main priority and is a leader in this market. The flow of orders over time for the five generations of the firm's focus products is much less volatile than for the remaining products in the firm's portfolio. The focus products are expected to improve roughly every 6-18 months, and customers plan accordingly.

By contrast, the non-focus products are a mixture of product types with different underlying end-uses for customers, different form factors based on industry standards, and different implementations of the underlying technology. We were able to group the non-focus products into fourteen categories: three variations on the focus product form factor, one 
grouping of subcomponents sold directly, one accessory product, eight alternate form factors, and a collection of miscellaneous products.

The relative physical volume measure provides a sense of how different the various products are from each other. The physical size of the non-focus products ranges from 0.1 to 9.0 times that of the physical size of the focus products. Although the underlying technology across all of the firm's products is based on the same scientific principles, the end products across these non-focus groupings are dramatically different not only from the focus products, but also from each other.

Figure 1A shows the shares of shipment volume over time for each of the focus product generations and the grouping of all non-focus products ${ }^{1}$. Figure 1B shows the shares of non-focus shipment volume over time for each type of non-focus product. Each shaded region in Figure 1B is a unique non-focus product grouping.

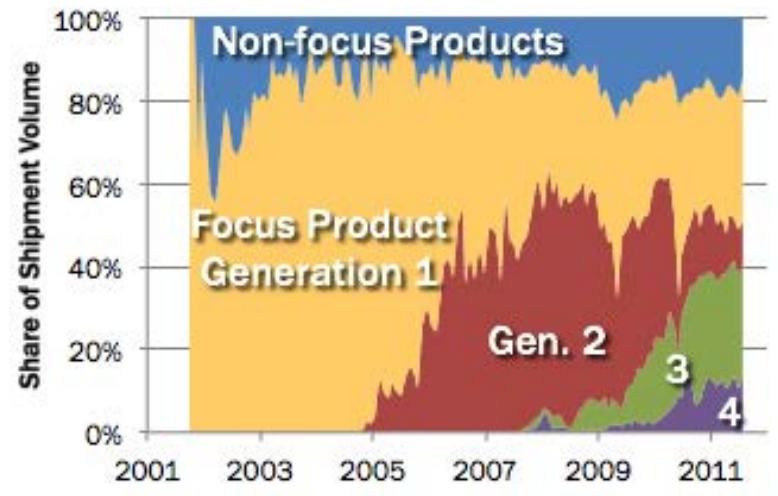

A: Product grouping shares of weekly shipment volume for generations of the focus product and the collection of non-focus products

Note: Product share of generation $\mathbf{5}$ is too small to see with this plot.

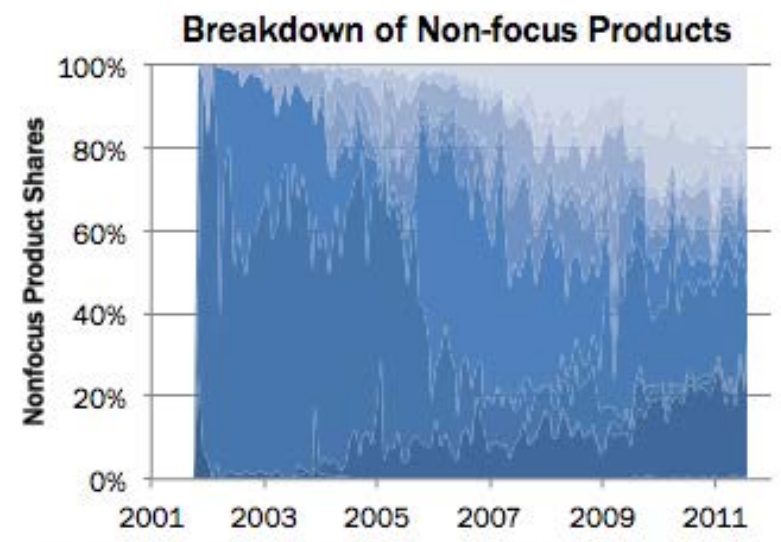

B: Relative shares of non-focus product types breakdown of the 14 different non-focus product types as shares of the total non-focus shipment volume

Figure 1

Beyond core product differences, there is an additional level of variety within products due to customers often requesting specific variations including tailored performance specifications, additional required tests, or cosmetic alterations (such as label placement). Each product, including each customization, receives a distinct part number. These customized parts can be produced in the facility for a long period of time or can be one-time orders

\footnotetext{
${ }^{1}$ To facilitate visual illustration of patterns over time, all figures show four-week averages of variables being portrayed.
} 
over its 10-year history. The facility has manufactured 1,139 specific variations across the five types of focus products and 5,818 specific variations across the fourteen types of nonfocus products as measured by unique part numbers, typically producing multiple units of each variation.

3.2.1. Measures We utilize the data detailed above to create four measures of product heterogeneity - the share of non-focus products, the generational overlap index (which captures the variety of product generations produced contemporaneously on the line), and customization indices for both focus and non-focus products (based on the customerspecific product requests).

Using the shipment data we calculate shipment volumes by product grouping and use this by-grouping data to calculate our heterogeneity measures. The share of non-focus products is our first measure of product heterogeneity on the line. Figure 1A shows the share of non-focus products over time.

Our second measure of product heterogeneity is a variant of the Herfindahl index that captures the mix of focus product generations being produced contemporaneously on the line. Two recent studies on the impact of product heterogeneity on productivity have used the Herfindahl index to aggregate data across types of products or tasks into a single term representing the variety of products on the line [Wiersma (2007), Staats and Gino (2011)]. This index accounts for changes in product mix more broadly than would a measure of the share of one type of product. The Herfindahl index, or Herfindahl-Hirschman index, is the sum of squared shares, $s$, of the variable of interest:

$$
H=\sum_{i=1}^{N} s_{i}^{2}
$$

Our index of co-production of different generations of the focus products is one minus the Herfindahl index of shares of those products. This definition facilitates interpretation because the index increases with increasing heterogeneity of products produced. We refer to this as our generational overlap index:

$$
G=1-\sum_{i=1}^{5} s_{i}^{2}
$$

Importantly, this measure is based only on generations of focus products; non-focus products are sufficiently heterogeneous as to lack a natural classification into generations. 
The degree of generational overlap is increasing in $G$. $G$ takes on a value of 0 when only one generation is being produced. As the number of generations produced at a given time increases, the value of $G$ rises. $G$ also increases as the shares of different generations being produced become more equal. Figure $2 \mathrm{~A}$ shows a plot of our generational overlap index.

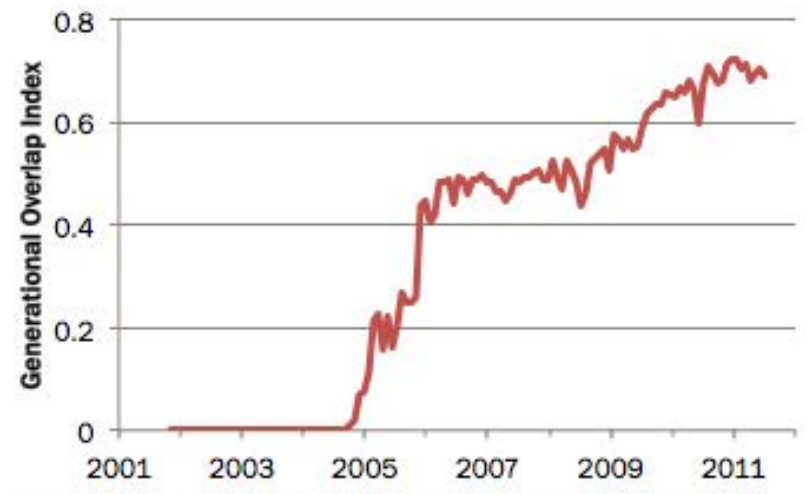

A: Generational overlap index for focus products

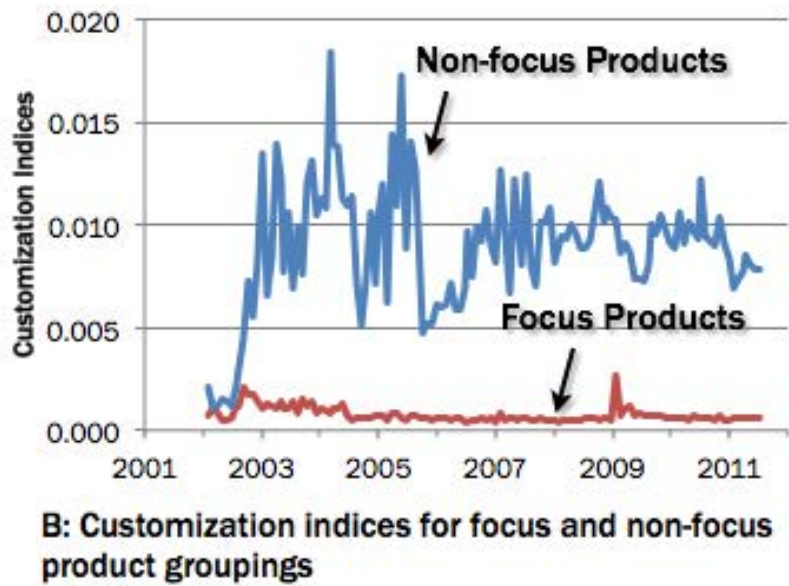

Figure 2

This figure shows the increasing generations of the focus product on the line over time. The increase in $G$ arises because, as shown in Figure 1A, the introduction of new generations does not result in the phasing out of previous generations.

We define two measures - which we call our customization indices $(M)$ - to capture product customizations within our focus and non-focus product groupings undertaken by the firm to meet specific customer requests. These measures, for focus and non-focus products respectively, are total part numbers for each product category divided by the shipment volume of that product category. We denote these part numbers per volume measures as $M_{f, t}$ and $M_{n, t}$. Figure 2B shows a plot comparing this measure for focus products and non-focus products.

As can be seen in Figure 2B, the ratio of part numbers to shipment volume is much higher for the non-focus products than the focus products. Of course, the number of focus products produced is more than four times the number of non-focus products. Hence the total number of customizations of focus products is greater than the number of customizations of non-focus products. 
3.2.2. Variation in the Difficulty of Producing Different Products Certain products may be more difficult to produce than others. Our models include measures of the share of non-focus products to capture a major likely source of differences in difficulty. To investigate this issue further, we collected data on the process steps required for each generation of the focus products and three different measures of the difficulty of each of those steps: the category assigned to each process step in the firm's training system, the time required to teach new workers each of the process steps as part of their training system, and the difficulty (on a scale of 1-5) assigned by engineers to each of the process steps. We collected data on all three of these measures in October 2011 through the surveys described in section 3.1.2. To create weekly measures of the difficulty of the products being produced, we multiplied the process difficulty measure by the number of that type of process that went into the focus products shipped in a given week. For example, the company's training system has three categories for processes: simple processes, for which a machine conducts the primary action; skill-based processes, which require some training; and criteria-based processes, which require the direct line worker to meet a particular criteria before passing the product on to the next process step. We have trainer categorization of all 77 process steps identified for the focus product generations, training time for each, and engineer difficulty rank for each.

Figure 3 shows over-time plots of: a) shares of levels of engineer difficulty ranking, b) shares of levels of training times, and c) shares of trainer categorization. The three metrics (engineering rank, training time, trainer categorization) give a relatively consistent picture of the evolution of the difficulty of processes within the factory: as the focus products have evolved through their generations and become more technologically complex, the plant has shifted towards more criteria-based processes which require longer training times and which are perceived by engineers to be more difficult processes. At the same time, the more complex products require fewer engineer-ranked simple processes and fewer very-short-training-time processes.

\section{3. $\quad$ Empirical Models}

To analyze the organization's learning rate, we begin with the traditional learning model. We then expand this model to incorporate measures of product heterogeneity and knowledge depreciation. We conclude by looking at transfer of knowledge across product generations [Epple et al. (1991, 1996), Benkard (2000)]. 

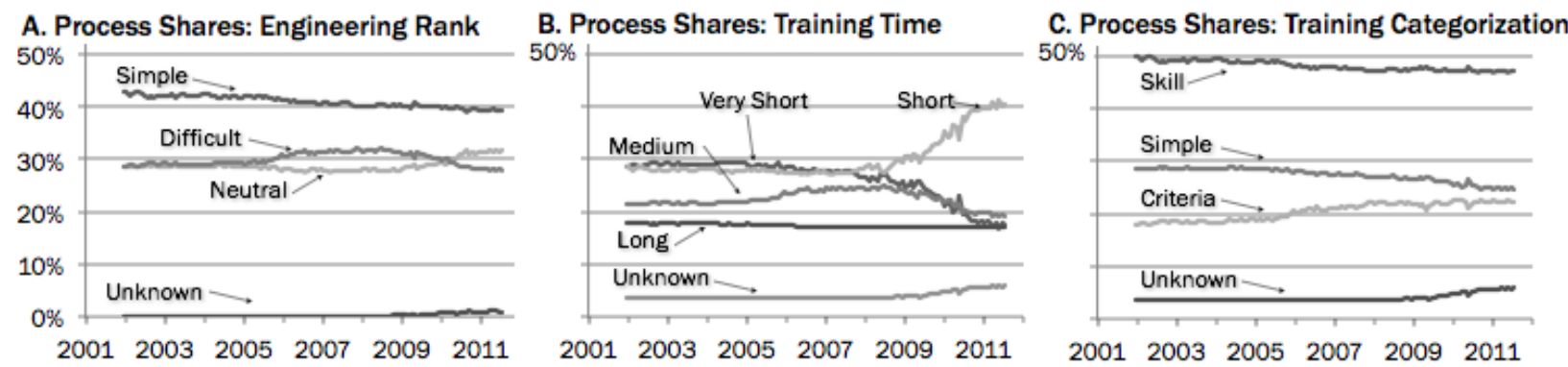

Figure 3

3.3.1. Foundational Learning Model We begin with a basic model of firm productivity that incorporates learning and labor input

$$
\ln \left(q_{t}\right)=\beta_{0}+\beta_{1} \ln \left(Q_{t-1}\right)+\beta_{3} \ln \left(L_{t}\right)+\epsilon_{t}
$$

where $q_{t}$ is the production volume in week $t$ as measured by products shipped, $Q_{t}$ is the cumulative production volume through week $t$ also as measured by products shipped, $L_{t}$ is the labor input as measured by the total number of line workers employed in week $t$, and $\epsilon_{t}$ is the error term [Argote (2013)].

To investigate whether the incremental gain from learning varies over time, we add a quadratic experience term, $\ln \left(Q_{t-1}\right)^{2}$. To examine the impact of the mix of non-focus versus focus products on the firm's overall productivity, we add the share of non-focus products shipped in week $t, s_{n, t}$. To analyze the impact of the mix of generations of focus products on the line on the firm's overall productivity, we include our focus product generational overlap index, $G_{t}$, as defined previously in section 3.2.1. To capture the impact of buyer-requested customizations on the firm's overall productivity we include our two customization indices, part numbers per unit for focus products, $M_{f, t}$ and part numbers per unit for non-focus products, $M_{n, t}$, as defined previously in section 3.2.1:

$$
\ln \left(q_{t}\right)=\beta_{0}+\beta_{1} \ln \left(Q_{t-1}\right)+\beta_{2} \ln \left(Q_{t-1}\right)^{2}+\beta_{3} \ln \left(L_{t}\right)+\beta_{4} s_{n, t}+\beta_{5} G_{t}+\beta_{6} M_{f, t}+\beta_{7} M_{n, t}+\epsilon_{t}
$$

3.3.2. Knowledge Retention We next extend the model to investigate whether knowledge depreciates. Following Argote et al. (1990), we replace cumulative production, $Q$, with a measure, $K$, that allows for potential depreciation:

$$
K_{t}=\lambda K_{t-1}+q_{t}
$$

If knowledge depreciates, $\lambda<1$. If there is no depreciation of knowledge, $\lambda=1$. In the latter case of no knowledge depreciation, this measure reduces to the cumulative output measure in the previous section. 
3.3.3. Learning Model with Cross-Product Knowledge Transfer We next incorporate knowledge transfer into the model detailed in the preceding section 3.3.1. We generalize the knowledge variable to permit differences in transfer of knowledge across products. This model is similar to the transfer model introduced in [Epple et al. (1991)] and further developed in [Epple et al. (1996)]. The model is:

$$
\begin{aligned}
& \ln \left(q_{t}\right)=\beta_{0}+\beta_{1} \ln \left(K_{t-1}\right)+\beta_{3} \ln \left(L_{t}\right)+\beta_{4} s_{n, t}+\beta_{5} G_{t}+\beta_{6} M_{f, t}+\beta_{7} M_{n, t}+\epsilon_{t} \\
& \text { where } K_{t}=\sum_{i} s_{i, t} K_{i, t} \\
& K_{i, t}=Q_{i, t}+\gamma\left(Q_{t}-Q_{i, t}\right) \\
& s_{i, t}=\frac{q_{i, t}}{q_{t}}
\end{aligned}
$$

To simplify the exposition, we do not incorporate depreciation in the above. As in our model from the preceding section, it is straightforward to incorporate depreciation, and we do so at the appropriate juncture in our analysis. In defining knowledge when there are differences in cross-product transfer, it is necessary to adopt a specification of the way in which knowledge about production of individual products aggregates to overall knowledge employed in production. In a joint-product environment, it is inherent that there is not a separate productivity measure for each product. Hence, inference about transfer across products must be made from information about overall productivity of the suite of products produced in each period. Our specification of the knowledge variable, $K_{t}$, in equation (8) weights knowledge specific to product $i, K_{i, t}$, by share of the product produced at date $t, s_{i, t}$. The weighing of $K_{i, t}$ by product shares to form $K_{t}$ is based on the logic that knowledge about product $i$ used in production is proportional to the share of product $i$ being produced. This share-weighting formulation is, we believe, the most natural specification, but it is nonetheless an important assumption underlying our analysis of transfer. This model permits each product to accumulate knowledge from its own past production, $Q_{i, t}$, and to benefit from possible transfer of knowledge from other products $\left(Q_{t}-Q_{i, t}\right)$. Parameter $\gamma$ measures the proportion of knowledge gained from production of other products that is transferred to enhance knowledge for production of product $i$. Our previous model in equation 6 implicitly sets $\gamma$ equal to 1.

The transfer specification above assumes symmetry in transfer of knowledge across products, i.e., $\gamma$ is the same for all products. We extend this model of knowledge accumulation to allow potential asymmetries in knowledge transfer across products. 
We explore whether there is differential transfer of knowledge by introducing four transfer parameters that capture transfer from non-focus products to focus products $\left(\gamma_{n 2 f}\right)$, transfer from focus products to non-focus products $\left(\gamma_{f 2 n}\right)$, transfer "up" the generational hierarchy (from older focus products to newer products) $\left(\gamma_{u}\right)$, and transfer "down" the generational hierarchy (from newer focus products to older focus products) $\left(\gamma_{d}\right)$. This yields the following specification of knowledge accumulation for our six products:

$$
\begin{aligned}
& K_{1, t}=Q_{1, t}+\gamma_{d}\left(Q_{2, t}+Q_{3, t}\right)+\gamma_{n 2 f} Q_{n, t} \\
& K_{2, t}=Q_{2, t}+\gamma_{u}\left(Q_{1, t}\right)+\gamma_{d}\left(Q_{3, t}\right)+\gamma_{n 2 f} Q_{n, t} \\
& K_{3, t}=Q_{3, t}+\gamma_{u}\left(Q_{1, t}+Q_{2, t}\right)+\gamma_{n 2 f} Q_{n, t} \\
& K_{n, t}=Q_{n, t}+\gamma_{f 2 n}\left(Q_{1, t}+Q_{2, t}+Q_{3, t}\right)
\end{aligned}
$$

where $K_{1}$ to $K_{3}$ are knowledge for our focus product generations and $K_{n}$ is knowledge for our non-focus products. We aggregate generations 3,4 , and 5 of the focus product into one generation to avoid proliferation of parameters. As is evident from Figure 1A, generations 3 and 4 were introduced at approximately the same time. These generations, as well as generation 5, share common technological advances that distinguish them from both first and second generation products. Production of generation 5 was exceedingly small during the time frame of our data. Thus, $K_{1}$ is knowledge for generation $1, K_{2}$ is knowledge for generation 2 , and $K_{3}$ is knowledge for generations 3-5.

\section{Results}

We first present results from the model in equation 6 which assumes that each product benefits equally from all prior units of all products produced. We then follow with results for the generalization in Section 3.3.3 that allows differential knowledge transfer across products.

\subsection{Organizational Learning}

We report and discuss results obtained when estimating our models by ordinary least squares, in anticipation of our later finding that our results are robust to instrumenting for the potential endogeneity of labor and our product heterogeneity variables. All models reported in this paper are estimated with weekly data.

It is instructive to begin with the series of results presented in Table 4 that do not incorporate cross-product transfer or depreciation. The baseline model in column (1) and 
Table 4 Estimation results: Learning model with part number per volume measures.

\begin{tabular}{|c|c|c|c|c|c|c|c|}
\hline & (1) & $(2)$ & (3) & (4) & $(5)$ & (6) & $(7)$ \\
\hline $\begin{array}{c}\beta_{1} \text {, Experience } \\
\ln \left(Q_{t-1}\right)\end{array}$ & $\begin{array}{l}0.548^{* * *} \\
(0.100)\end{array}$ & $\begin{array}{l}3.794^{* * *} \\
(0.614)\end{array}$ & $\begin{array}{l}2.785^{* * *} \\
(0.403)\end{array}$ & $\begin{array}{l}0.434 \\
(0.316)\end{array}$ & $\begin{array}{l}0.283^{* * *} \\
(0.041)\end{array}$ & $\begin{array}{l}0.283^{* * *} \\
(0.041)\end{array}$ & $\begin{array}{l}0.276^{* * *} \\
(0.041)\end{array}$ \\
\hline $\begin{array}{l}\beta_{2} \text {, Experience Sq. } \\
\quad\left(\ln \left(Q_{t-1}\right)\right)^{2}\end{array}$ & & $\begin{array}{l}-0.103^{* * *} \\
(0.022)\end{array}$ & $\begin{array}{l}-0.076^{* * *} \\
(0.013)\end{array}$ & $\begin{array}{l}-0.005 \\
(0.010)\end{array}$ & & & \\
\hline $\begin{array}{l}\beta_{3}, \text { Labor } \\
\quad \ln \left(L_{t}\right)\end{array}$ & $\begin{array}{l}0.206 \\
(0.280)\end{array}$ & $\begin{array}{l}0.562^{*} \\
(0.312)\end{array}$ & $\begin{array}{l}0.477^{* * *} \\
(0.156)\end{array}$ & $\begin{array}{l}0.270^{* * *} \\
(0.070)\end{array}$ & $\begin{array}{l}0.259^{* * *} \\
(0.072)\end{array}$ & $\begin{array}{l}0.274^{* * *} \\
(0.075)\end{array}$ & $\begin{array}{l}0.245^{* * *} \\
(0.067)\end{array}$ \\
\hline $\begin{array}{l}\beta_{4} \text {, Share Non-focus } \\
s_{n, t}\end{array}$ & & & $\begin{array}{l}-1.992^{* * *} \\
(0.335)\end{array}$ & $\begin{array}{l}-0.584 \\
(0.415)\end{array}$ & $\begin{array}{l}-0.634 \\
(0.402)\end{array}$ & $\begin{array}{l}-0.603 \\
(0.402)\end{array}$ & $\begin{array}{l}-0.674 \\
(0.427)\end{array}$ \\
\hline $\begin{array}{l}\beta_{5}, \text { Gen. Overlap } \\
\quad G_{f, t}\end{array}$ & & & $\begin{array}{l}0.789^{* * *} \\
(0.255)\end{array}$ & $\begin{array}{l}0.505^{* * *} \\
(0.127) \\
\end{array}$ & $\begin{array}{l}0.480^{* * * *} \\
(0.122)\end{array}$ & $\begin{array}{l}0.497^{* * *} \\
(0.123)\end{array}$ & $\begin{array}{l}0.481^{* * *} \\
(0.128)\end{array}$ \\
\hline $\begin{array}{l}\beta_{6} \text {, Cust.: Focus } \\
\quad M_{f, t}\end{array}$ & & & & $\begin{array}{l}-810.422^{* * *} \\
(87.219)\end{array}$ & $\begin{array}{l}-813.042^{* * *} \\
(86.192)\end{array}$ & $\begin{array}{l}-810.861^{* * *} \\
(87.343)\end{array}$ & $\begin{array}{l}-813.434^{* * *} \\
(82.585)\end{array}$ \\
\hline $\begin{array}{l}\beta_{7} \text {, Cust.: Non-focus } \\
\quad M_{n, t}\end{array}$ & & & & $\begin{array}{l}-23.165^{* * *} \\
(5.061)\end{array}$ & $\begin{array}{l}-23.623^{* * *} \\
(4.940)\end{array}$ & $\begin{array}{l}-23.447^{* * *} \\
(4.960) \\
\end{array}$ & $\begin{array}{l}-24.024^{* * *} \\
(4.928)\end{array}$ \\
\hline Eng. Rank Avg. & & & & & & $\begin{array}{l}-0.464 \\
(0.996)\end{array}$ & \\
\hline $\begin{array}{l}\text { Depreciation } \\
\quad \lambda \\
\end{array}$ & & & & & & & $\begin{array}{l}1.001 * * * a \\
(0.002)\end{array}$ \\
\hline Observations & 461 & 461 & 461 & 461 & 461 & 461 & 461 \\
\hline R-squared & 0.834 & 0.860 & 0.880 & 0.956 & 0.956 & 0.956 & 0.956 \\
\hline Durbin-Watson & 1.536 & 1.817 & 1.958 & 1.873 & 1.873 & 1.873 & 2.710 \\
\hline Log Likelihood & -158.259 & -120.279 & -84.990 & 144.871 & 144.685 & 144.813 & 144.800 \\
\hline
\end{tabular}

${ }^{a}$ Statistical significance is marked here as difference from 0 , consistent with other parameters, however we are interested in difference from 1 for the depreciation parameter.

all subsequent specifications show significant learning by doing as well as significant coefficients for labor input. The model in column (2) incorporates a quadratic in cumulative past production to investigate possible diminution in the effect of learning as experience accumulates. The significant negative coefficient on this term suggests that the rate of learning diminishes as cumulative production increases ${ }^{2}$. As we show below, however, our exceptionally rich data set permits us to look into the black box to shed light on the mech-

\footnotetext{
${ }^{2}$ The peak of this quadratic function occurs well beyond the cumulative volume observed in our data. Hence, this specification implies that learning by doing continues throughout the entire production period that we observe.
} 
anisms at work and demonstrate that the evidence does not, in fact, imply a decline in the benefits of learning.

In column (3), we add the share of non-focus products, $s_{n, t}$, and the generationaloverlap index for focus products, $G_{t}$. We find that a higher proportion of non-focus products decreases productivity. As we detailed in Section 3.2, these products differ in many important respects from the focus products. In contrast, increasing generational overlap in production increases productivity. Our finding that this form of product heterogeneity increases productivity is striking. Before turning to a more detailed exploration of this finding, we explore the effects of controlling for other factors that can impact productivity. In column (4), we introduce measures of customizations arising from buyer-specific requests for product modifications, with separate customization indices for focus and nonfocus products. We find that increases in customizations per unit of both product types reduce productivity. This finding about the difficulty of producing many variations of core products is in line with our qualitative findings from interviews with engineers. Specifically, one engineer stated "Things are ... customized because we try to keep market share. The mix on the line of multiple shells and types of enclosures is hard."

To interpret the customization coefficients, it is useful to convert them to elasticities - the percent change in production from a one percent change in customization holding other variables constant. With the dependent variable expressed in logarithmic form, the elasticity of output with respect to any non-logged independent variable, $x$, is $E_{q, x}=\beta_{x} \bar{x}$. We find that focus products have a customization index elasticity of -0.20 ; a $1 \%$ increase in customizations reduces production by $0.2 \%$. Our non-focus products have a customization index elasticity of -0.07 . These elasticities show that a $1 \%$ increase in custom part numbers per unit volume of focus products has an adverse effect on productivity that is three times as large as a $1 \%$ increase in custom part numbers per unit volume of a non-focus product. Interestingly, the coefficient of the share of non-focus products becomes smaller and less significant in column (4), suggesting that the customizations (part numbers per volume) account for part of the negative effect of the share of non-focus products. The effect of generational overlap remains positive and significant when the customization variables are included.

Once we control for buyer-specific product modifications, as we do in columns (4) and (5), we no longer find evidence of a diminution in the rate of learning (the quadratic term in 
cumulative output becomes small in magnitude and statistically insignificant). This finding demonstrates the importance the kind of rich product detail that we have been fortunate to obtain for this analysis can play in understanding the dynamics of learning in a multiproduct facility. Absent this extensive detail, we could have mistakenly concluded that the benefit of learning by doing in the plant diminished over time.

Our ability to characterize three different types of product heterogeneity also offers an opportunity to reconcile past results from research on organizational learning with other results from operations management. Our finding with respect to the negative impact of buyer-specific product customizations echoes findings in the operations management literature that frequent product changes are costly. Our finding with respect to the benefits of producing overlapping generations of focus products echoes prior findings in the learning literature about the potential benefits to productivity of product variety. Thus, producing different generations of the same product helps productivity, while product customizations harm productivity. We examine in a subsequent section whether the positive effect of co-producing different generations of focus products is explained by knowledge transfer.

In column (6) in Table 4, we add the engineering difficulty measure. This measure has the anticipated algebraic sign showing that an increase in engineering difficulty decreases productivity. This variable, however, is not statistically significant and including it does not affect our other coefficients. Hence, column (5) is our preferred model from our analysis thus far ${ }^{3}$.

It is useful to interpret the quantitative magnitudes of the estimates in column (5). The coefficients of the logarithm of experience and the logarithm of labor are elasticities. Hence, a $1 \%$ increase in experience increases output by $0.28 \%$ holding all else constant. A $1 \%$ increase in labor increases output $0.26 \%$ holding all else constant. The elasticity of output with respect to share non-focus is -0.08 . The elasticity of output with respect to the generational overlap index is 0.90. This is a strikingly large effect. As Figure $2 \mathrm{~A}$ shows, the generational overlap index increased from zero to 0.5 from 2005 to 2006. This coupled with the coefficient on 0.48 in column (5) imply an increase in production of $27 \%$ from the increase in generational overlap during that period. The index continues to rise

\footnotetext{
${ }^{3}$ We see similar results when we add in our other two process difficulty measures, share of training categorization and average training time. In these cases as well the measures themselves are not significant and have minimal change to the magnitudes and no change to the significance levels of the core variables in the model.
} 
in subsequent years to 0.75 . Hence, over the period of our data, the generational overlap index is associated with a total increase in productivity of $43 \%$. We explore these and other managerial implications in greater detail in a later section of the paper.

4.1.1. Endogeneity \& Robustness One might be concerned about endogeneity in our product mix variables if the firm intentionally alters their product mix in a given week to improve productivity. We investigated potential endogeneity using instrumental variables. Order arrivals provide ideal variables for constructing instruments. Order placement is driven by customer demand and the firm does not restrict the number of orders accepted by its sales staff. Thus, order flow is exogenous to our production facility.

We investigated potential endogeneity of all independent-variables in column (5) of Table 4 except lagged cumulative output. We created instruments as follows. We calculated for each week the share of non-focus products in orders, a generational overlap index from orders, and customization indices from orders. We then calculated six-week averages of each of these variables, and used the one-period lag of each these as instruments. As an instrument for the logarithm of labor, we used the lagged logarithm of labor. These are strong instruments. The first-stage F-statistics were 24 or higher for each of the five potentially endogenous regressors. Using these instruments, we tested for exogeneity of the five potentially endogenous variables, and found p-values above 0.4 for all variables except share non-focus, for which we obtained a p-value of 0.09 . Thus, we find no evidence to reject exogeneity of any right-hand-side variable except, possibly, share non-focus.

In Table 5 we report instrumental variable estimates. For ease of comparison, column (5) of Table 4 is repeated as column (1) of Table 5. In column (2), we report the results of instrumental variable (IV) estimation treating all but lagged cumulative output as endogenous and using the five instruments described in the preceding paragraph. In column (3) we report results of instrumenting only for share non-focus using the lagged six-week average of share non-focus described in the preceding paragraph. In column (2), the estimate of the coefficient of share non-focus increases substantially relative to column (1). In column (3), the estimate of share non-focus is much higher and is statistically significant.

The change in the coefficient of share non-focus with IV estimation is intuitive. A perspicacious manager might choose to increase the share of the more-difficult-to-produce non-focus products during weeks when the production process is going quite well (i.e., 
Table 5 Estimation results: Instrumented learning model with part number per volume measures.

\begin{tabular}{|c|c|c|c|}
\hline & $(1)$ & $(2)$ & $(3)$ \\
\hline $\begin{array}{l}\beta_{1}, \text { Experience } \\
\quad \ln \left(Q_{t-1}\right)\end{array}$ & $\begin{array}{l}0.283^{* * *} \\
(0.041)\end{array}$ & $\begin{array}{l}0.295^{* * *} \\
(0.073)\end{array}$ & $\begin{array}{l}0.323^{* * *} \\
(0.043)\end{array}$ \\
\hline $\begin{array}{c}\beta_{3}, \text { Labor } \\
\quad \ln \left(L_{t}\right)\end{array}$ & $\begin{array}{l}0.259^{* * *} \\
(0.072)\end{array}$ & $\begin{array}{l}0.293^{* * *} \\
(0.076)\end{array}$ & $\begin{array}{l}0.302^{* * *} \\
(0.071)\end{array}$ \\
\hline $\begin{array}{c}\beta_{4} \text {, Share Non-focus } \\
s_{n, t}\end{array}$ & $\begin{array}{l}-0.634 \\
(0.402)\end{array}$ & $\begin{array}{l}-1.487 \\
(1.080)\end{array}$ & $\begin{array}{l}-2.409^{* * *} \\
(0.820)\end{array}$ \\
\hline $\begin{array}{l}\beta_{5}, \text { Generational Overlap } \\
G_{t}\end{array}$ & $\begin{array}{l}0.480^{* * *} \\
(0.122)\end{array}$ & $\begin{array}{l}0.425^{*} \\
(0.242)\end{array}$ & $\begin{array}{l}0.409 * * * \\
(0.130)\end{array}$ \\
\hline $\begin{array}{l}\beta_{6} \text {, Customization: Focus } \\
\quad M_{f, t}\end{array}$ & $\begin{array}{l}-813.042^{* * *} \\
(86.192)\end{array}$ & $\begin{array}{l}-747.970^{* * *} \\
(214.534)\end{array}$ & $\begin{array}{l}-589.099^{* * *} \\
(125.913)\end{array}$ \\
\hline $\begin{array}{l}\beta_{7} \text {, Customization: Non-focus } \\
M_{n, t}\end{array}$ & $\begin{array}{l}-23.623^{* * *} \\
(4.940)\end{array}$ & $\begin{array}{l}-28.012^{* *} \\
(12.601)\end{array}$ & $\begin{array}{l}-39.203^{* * *} \\
(8.353)\end{array}$ \\
\hline Observations & 4661 & 461 & 461 \\
\hline$R^{2}$ & 0.956 & 0.954 & 0.951 \\
\hline Durbin-Watson & 1.873 & 1.913 & 1.943 \\
\hline
\end{tabular}

$\left.\epsilon_{t}>0\right)$. By thus increasing $s_{n, t}$ during weeks of high $\epsilon_{t}$, the manager creates a positive correlation between the $s_{n, t}$ and $\epsilon_{t}$. This imparts an upward bias to the coefficient of $s_{n, t}$ when the equation is estimated by least squares. IV estimation removes this upward bias, and, hence, yields a larger estimate of the cost of increasing the share of non-focus products. Note, relatedly that with IV estimation the coefficient of the customization index, $M_{n, t}$, declines in magnitude. This too is intuitive, because bias in the coefficient of an endogenous variable impart bias to coefficients of variables that are correlated with the endogenous variable. Variables $M_{n, t}$ (the non-focus customization index) and $s_{n, t}$ (the share of nonfocus products) are negatively correlated. Eliminating the bias in the coefficient of $s_{n, t}$ also eliminates bias the coefficient of $M_{n, t}$.

While the effect of correcting for endogeneity of $s_{n, t}$ is quite intuitive, the correction does not change our substantive findings or conclusions. Indeed, aside from the shift in the coefficients of $s_{n, t}$ and $M_{n, t}$, the coefficients of other variables are little affected. Overall, then, the IV estimates ratify our findings and conclusions with respect to learning in the multi-product environment that we study.

We investigated robustness of our generational overlap measure by reducing the exponent to a level of $1.5, G=1-\sum_{i=1}^{5}\left(\frac{q_{i t}}{q_{t}}\right)^{1.5}$, from the baseline value of $2, G=1-\sum_{i=1}^{5}\left(\frac{q_{i t}}{q_{t}}\right)^{2}$. 
This allows the generational overlap index to give larger weight to product generations with smaller shares. Our results are robust to this alternate calculation of the generational overlap index ${ }^{4}$. We verified the robustness of our results to adding controls for differences in process difficulty across our generations of focus products.

We also investigated capital investment as an alternative source of productivity growth. The firm that we study did not make significant new capital investments in the facility during the timeframe of our analysis. From interviews and on-site observation, we learned that new testing equipment was developed within the plant that permitted more rapid testing and thereby potentially enhanced productivity. This development in the plant can be thought of as embedding knowledge from learning by doing into equipment. Experience with production created the knowledge base that led engineers to develop insights leading to improvements in testing equipment and procedures. It is nonetheless of interest to investigate whether this testing innovation had a significant effect on productivity. To do so, we created a dummy variable, $D_{t}$, which is equal to 0 before the new testing equipment was introduced and equal to 1 afterward. Table 6 shows the results of the inclusion of this dummy variable and an interaction term of this dummy variable with experience. Neither the dummy variable nor the interaction term themselves are significant and they do not impact our results. Thus, our results are robust to the inclusion of this control for improved testing equipment.

In additional analysis, we investigated whether the residuals exhibit serial correlation in our preferred model in column (5) of Table 4 by calculating Q-statistics. We found no evidence of serial correlation up through 12 lags, but significant correlation at the $13^{\text {th }}$ lag. An effect at the $13^{\text {th }}$ lag could potentially arise, for example, if the facility exerts some extra effort at the end-of-quarter to speed shipment of completed products to meet delivery requests. Estimating the model in column (5) with an autorogressive term at the $13^{\text {th }}$ lag, we obtain a significant but modest auroregressive coefficient of 0.24 . The coefficients and significance levels of the variables in column (5) were otherwise not notably affected aside from an increase in the significance of share non-focus. Hence, there is, overall, little serial correlation, and no effect on our conclusions when we account for the modest serial correlation evident at quarterly frequency.

\footnotetext{
${ }^{4}$ Concern has been raised about potential bias in the Herfindahl Index, the basis for our generational overlap index, due to measurement error, [Hall (2005)]. Bias can arise when the index is calculated from count data with a small number of counts. Our data do not suffer from this problem because our product counts are exceedingly large. For a discussion of the merits of the Herfindahl index relative to other indices, see Palan (2010).
} 
Table 6 Estimation results: Inclusion of capital dummy variable.

\begin{tabular}{lll}
\hline & \multicolumn{1}{c}{$(1)$} & \multicolumn{1}{c}{$(2)$} \\
\hline$\beta_{1}$, Experience & $0.276^{* * *}$ & $0.276^{* * *}$ \\
$\ln \left(Q_{t-1}\right)$ & $(0.046)$ & $(0.049)$ \\
\hline$\beta_{3}$, Labor & $0.254^{* * *}$ & $0.254^{* * *}$ \\
$\ln \left(L_{t}\right)$ & $(0.068)$ & $(0.090)$ \\
\hline$\beta_{4}$, Share Non-focus & $-0.672^{*}$ & -0.672 \\
$s_{n, t}$ & $(0.406)$ & $(0.426)$ \\
\hline$\beta_{5}$, Generational Overlap & $0.487^{* * *}$ & $0.486^{* * *}$ \\
$G_{f, t}$ & $(0.122)$ & $(0.123)$ \\
\hline$\beta_{6}$, Customization: Focus & $-816.408^{* * *}$ & $-816.383^{* * *}$ \\
$M_{f, t}$ & $(87.752)$ & $(87.768)$ \\
\hline$\beta_{7}$, Customization: Non-focus & $-23.979^{* * *}$ & $-23.988^{* * *}$ \\
$M_{n, t}$ & $(5.044)$ & $(5.136)$ \\
\hline Capital & 0.022 & 0.006 \\
$D_{t}$ & $(0.036)$ & $(1.186)$ \\
\hline Interaction: Capital \& Experience & & 0.001 \\
$D_{t} \times \ln \left(Q_{t-1}\right)$ & & $(0.067)$ \\
\hline \hline Observations & 461 & 461 \\
\hline$R^{2}$ & 0.956 & 0.956 \\
\hline Durbin-Watson & 1.878 & 1.878 \\
\hline Log Likelihood & 144.967 & 144.967 \\
\hline Note: ${ }^{* *},{ }^{* * *}$ denote statistical significance at the $10 \%$, \\
$5 \%$, and 1\% levels respectively. Newey-West robust standard \\
errors reported in parentheses. The constant term is omitted \\
for firm confidentiality. & &
\end{tabular}

\subsection{Knowledge Retention}

We next turn to investigation of knowledge retention. In column (7) of Table 4, we incorporate the depreciation parameter detailed in equation 7 . Here, we see that the depreciation parameter, previously set equal to one, is not significantly different from one, and we conclude that the facility does not exhibit forgetting or knowledge depreciation.

We also investigated the potential for confounding learning and time-varying influences unrelated to learning. To do this, we added a time trend to the model in column (7) of Table 4. We find the estimated coefficient of the time trend to be quantitatively small and statistically insignificant. The statistical significance of all other variables is unchanged, including an estimated depreciation parameter that does not differ from 1. 


\subsection{Knowledge Transfer}

A key and robust finding from our analysis thus far is that production of overlapping product generations enhances productivity. We turn to a more detailed investigation of transfer to better understand why this effect occurs. The framework in equation (9) is a generalization of the framework we have studied thus far, and reduces to the latter when all of the transfer parameters equal 1. We estimate this model by nonlinear least squares.

Table 7 Estimation results: Knowledge transfer model with part number per volume measures.

\begin{tabular}{|c|c|c|c|}
\hline & $(1)$ & $(2)$ & $(3)$ \\
\hline $\begin{array}{l}\beta_{1} \text {, Knowledge } \\
\quad \ln \left(K_{t-1}\right)\end{array}$ & $\begin{array}{l}0.287^{* * *} \\
(0.040)\end{array}$ & $\begin{array}{l}0.375^{* * *} \\
(0.060)\end{array}$ & $\begin{array}{l}0.285^{* * *} \\
(0.040)\end{array}$ \\
\hline $\begin{array}{l}\beta_{3}, \text { Labor } \\
\quad \ln \left(L_{t}\right)\end{array}$ & $\begin{array}{l}0.261^{* * *} \\
(0.066)\end{array}$ & $\begin{array}{l}0.203^{* * *} \\
(0.075)\end{array}$ & $\begin{array}{l}0.271^{* * *} \\
(0.065)\end{array}$ \\
\hline $\begin{array}{c}\beta_{4} \text {, Share Non-focus } \\
s_{n, t}\end{array}$ & $\begin{array}{l}-0.338 \\
(0.386)\end{array}$ & $\begin{array}{l}-0.229 \\
(0.404)\end{array}$ & $\begin{array}{l}-0.207 \\
(0.393)\end{array}$ \\
\hline $\begin{array}{l}\beta_{5} \text {, Generational Overlap } \\
\quad G_{t}\end{array}$ & $\begin{array}{l}0.603^{* * *} \\
(0.142)\end{array}$ & $\begin{array}{l}0.407^{* *} \\
(0.169)\end{array}$ & $\begin{array}{l}0.366^{* *} \\
(0.144)\end{array}$ \\
\hline $\begin{array}{l}\text { Partnums/Vol Focus } \\
\quad P P V_{f, t}\end{array}$ & $\begin{array}{l}-803.880^{* * *} \\
(77.801)\end{array}$ & $\begin{array}{l}-820.586^{* * *} \\
(81.416)\end{array}$ & $\begin{array}{l}-809.796^{* * *} \\
(79.894)\end{array}$ \\
\hline $\begin{array}{l}\text { Partnums/Vol Nonfocus } \\
\qquad P P V_{n, t}\end{array}$ & $\begin{array}{l}-21.619^{* * *} \\
(4.472)\end{array}$ & $\begin{array}{l}-21.182^{* * *} \\
(4.714) \\
\end{array}$ & $\begin{array}{l}-20.423^{* * *} \\
(4.720) \\
\end{array}$ \\
\hline $\begin{array}{l}\text { Transfer: Non-focus } \rightarrow \text { Focus } \\
\gamma_{n 2 f}\end{array}$ & $\begin{array}{l}0.590 \\
(1.720)\end{array}$ & $\begin{array}{l}6.725 \\
(5.267)\end{array}$ & $=0$ \\
\hline $\begin{array}{l}\text { Transfer: Focus } \rightarrow \text { Non-focus } \\
\quad \gamma_{f 2 n}\end{array}$ & $\begin{array}{l}-0.127 \\
(0.304)\end{array}$ & $\begin{array}{l}-0.133 \\
(0.525)\end{array}$ & $=0$ \\
\hline $\begin{array}{l}\text { Transfer: Older } \rightarrow \text { Newer Focus } \\
\gamma_{u}\end{array}$ & $\begin{array}{l}1.402^{* *} \\
(0.546)\end{array}$ & & \\
\hline Transfer: Older $\rightarrow$ Newer Focus, year 1 only & & $\begin{array}{l}3.037^{*} \\
(1.814) \\
\end{array}$ & $\begin{array}{l}2.948^{* *} \\
(1.215)\end{array}$ \\
\hline Transfer: Older $\rightarrow$ Newer Focus, after year 1 only & & $\begin{array}{l}-0.650 \\
(1.202)\end{array}$ & $\begin{array}{l}0.500 \\
(0.844)\end{array}$ \\
\hline $\begin{array}{l}\text { Transfer: Newer } \rightarrow \text { Older Focus } \\
\gamma_{d}\end{array}$ & $\begin{array}{l}-2.669^{* * *} \\
(0.793) \\
\end{array}$ & $\begin{array}{l}-1.899 \\
(1.212)\end{array}$ & $=0$ \\
\hline Observations & 461 & 461 & 461 \\
\hline$R^{2}$ & 0.957 & 0.958 & 0.957 \\
\hline Durbin-Watson & 1.937 & 1.918 & 1.924 \\
\hline Log Likelihood & 153.919 & 156.380 & 152.701 \\
\hline
\end{tabular}


Column (1) of Table 7 reports the results of estimating the model in equation (9). The coefficients of the knowledge variable, $K_{t-1}$, labor input, $L_{t}$, and each of the product heterogeneity terms $\left(s_{n, t}, G_{t}, M_{f, t}, M_{n, t}\right)$ retain similar magnitudes and significance levels as their counterparts in column (5) of Table 4. This similarity speaks to the robustness of our findings.

Turning to the estimates of the transfer parameters, we see, as expected, that transfer from older to newer focus products, $\gamma_{u}$, is substantial and statistically significant. Not surprisingly, the parameters capturing transfer between focus and non-focus products, $\gamma_{n 2 f}$ and $\gamma_{f 2 n}$, are insignificantly different from 0 . By contrast, the large negative value of the coefficient measuring transfer from newer to older products, $\gamma_{d}$, is unexpected. Introduction of newer products might entail production changes that adversely affect production of older products, as found by Levitt et al. (2013), but the magnitude and significance of the estimate in column (1) is unexpected, especially given that large volumes of the older products continue to be produced throughout the timeframe of our data. These results, however, match insights we gained from our discussions with the firm. One high-level manager stated "In general we focus our energy for making process improvements on newer generations of products. This makes our engineering investments more effective and requires less customer notification/qualification." This explanation corroborates that we would not expect improvements on newer products to transfer to older products.

We conjectured that estimated negative transfer to older products might be an artifact of failing to capture fully the timing of transfer of knowledge from older to newer products. Hence, we extended our transfer model further to investigate this issue. Prior research has found that transfer across facilities [Argote et al. (1990)], and across shifts within a facility [Epple et al. (1996)], is often most rapid during the period immediately after startup of the new facility or shift. Hence, we extend our transfer model to permit forward transfer during the first year of introduction of a new product to differ from forward transfer thereafter. We find, column (2) of Table 7, that estimated forward transfer during the first year is substantial while transfer thereafter is small and statistically insignificant. In addition, we find that the estimated negative transfer from newer to older products is smaller and no longer statistically significant. In column (3), we refine this model by dropping the insignificant coefficients of transfer between focus and non-focus products and the insignificant backward transfer coefficient. This model reinforces the conclusion that 
forward transfer occurs largely during the first year after introduction of a new product. Thereafter, learning continues to accumulate as increased cumulative production of a given product enhances productivity for that product, but cross-product transfer is small and statistically insignificant. We have investigated if these findings are sensitive to whether the initial forward transfer is assumed to occur over a shorter or longer period (fewer than 12 months or greater than 12 months) and have found that the fit of the model is not improved by departing from the assumed one-year period of forward transfer.

The forward-transfer estimate of 3 in column (3) of Table 7 suggests that, during the first year, a new product, $i$, benefits much more from transfer of the accumulated stock from prior production of other products than from its own production. The estimated value of 3 , while significantly different from 0 , is not significantly different from 1 . Hence, we do not reject the hypothesis that knowledge acquired per cumulative unit of a new product $i$ is the same as the knowledge transfer per unit from older products. Of course, during the first year of production of a new product, the cumulative production of older products dominates the cumulative production of the new product, making transfer the predominant contributor to productivity for the new product even if the transfer coefficient is 1 .

In looking across the models in Table 7, we see that the coefficient of the generational overlap index decreases as we move from one model to the next. This change supports our conclusion that a substantial component of the productivity enhancement from producing overlapping generations is captured by the rapid transfer of knowledge across product generations. The coefficient of the generational overlap index continues to be significant, however, pointing to synergies from co-production in addition to the benefits of transfer across generations. It is also useful to note that the estimates of the other (i.e., non-transfer) parameters of our model are similar across the three specifications in Table 7 . Hence, this analysis of transfer reinforces the robustness of our primary findings with respect to the importance of learning by doing.

In further analysis (not shown), we added a time trend to the model of column (3) of Table 7 and also allowed for possible depreciation of knowledge. We find that the time trend differs negligibly from zero and the depreciation parameter, $\lambda$, does not differ significantly from one. Hence, our findings with respect to both of these factors are unchanged; there is 
no "forgetting" and no evidence of gains in productivity associated with time, per se, as distinct from gains arising from learning.

As we have seen, the estimated forward transfer in the knowledge transfer specification of the model is quite large. These large gains were realized during times when there were no major new capital expenditures. How then were such large gains realized? Based on discussion with the managers of the firm, we learned that the firm developed and implemented innovations in production practices by leveraging experiences with early generations of products to enhance efficiency of production of newer products. Innovations in testing practices are one example. Managers and engineers cite innovations in testing that emerged from knowledge gained during production, innovations that led to internal reconfiguration of testing equipment and procedures to allow quicker testing of focus products and more flexibility for use across different generations of products and across product customizations. The flexibility developed from these innovations in testing practices may have played a role in facilitating the transfer of knowledge across product generations that we have found during the first year of new product introductions. In addition to facilitating knowledge transfer, these innovations in testing practices may also have served to embed important acquired knowledge in the testing routines, thereby facilitating the retention of knowledge that we have found in our analysis.

As a second example of productivity-enhancing knowledge acquisition, the firm discovered that "block" changes, which entail implementing changes simultaneously as a group or "block" rather than implementing a series of individual changes at different points in time, enhanced efficiency. This new approach was first applied and discovered to enhance productivity during implementation of a set of product changes required for compliance with new environmental regulations (specifically, the EU's Restriction on Hazardous Substances directive (RoHS)). This strategy often involves changes to components or subassemblies across product generations or across different products. These changes may help explain the firm's efficient transfer of knowledge across products, as learning is embedded in machine, component, or other hardware changes common across multiple products.

\section{Managerial Implications}

In addition to advancing the frontier in understanding organizational learning, quantification of learning in a multi-product environment provides valuable information for managers. Findings with respect to learning provide guidance about circumstances in which 
synergies across products can be expected as well as those in which there might be no synergies, or even adverse impacts of multi-product production. Regarding the former, we have seen that co-production of overlapping generations of a given product family can give rise to significant synergies. Our investigation of transfer between focus and non-focus products suggests that there is no synergy in learning across these two product families. Products in these two product families differ markedly from each other, and our results show that neither family benefits from knowledge acquired in producing the other. We have found that extensive product variety, such as that arising from customizing individual products to meet buyer needs, can lead to adverse effects on productivity. These findings suggest important considerations for firms in planning new production facilities, deciding which production activities should be housed in a given facility, in setting policy about the extent of product variation that will be undertaken in response to buyer requests for customization, and in taking account of learning-by-doing in anticipating future labor requirements. These findings can also be useful to firms in making judgments about price premia to set in order to make such customizations profitable.

Over the time frame of our analysis, the facility we study achieved more than a 16-fold increase in weekly production. It is instructive to provide an accounting of the role of various factors in enabling this increase. Our estimates in column (5) of Table 4 imply that a doubling of cumulative output permits increasing production by $22 \%$ holding labor and other factors (product mix and product customization rates) constant. Cumulative output doubled approximately 6.2 times over the period that we study. Hence, learning permitted increasing production by a multiple of 3.4 holding labor constant. The generational overlap index increased over the time period we studied from 0 to 0.75 . Holding labor and other factors (customizations and cumulative volume) constant, our estimates in column (5) of Table 4 imply that the increase in generational overlap would have permitted an increase in output by a multiple of 1.43. Labor input increased five fold, contributing a multiple of $5^{0.259}=1.52$. Over the time period we study, customizations for focus products were reduced markedly. During the last six months of the period we study, focus customizations were $60 \%$ lower that during the first six months. Other things constant, this contributed a proportionate increase in output of $e^{-813(0.00156-0.00593)}=2.2$, and provides a striking illustration of the magnitude of the productivity effects of providing buyer-specific product 
variants. Turning to non-focus products, we find negligible difference in the six-month customization average at the end as compared to the six-month average at the beginning of our sample period. Hence, other things constant, we find no effect of non-focus customizations in accounting for the increased output at the end relative to the beginning of the period we study. The change in share non-focus products was modestly lower at the end than at the beginning of the production period, giving rise to only a 1.03 multiple to production evaluated with the share non-focus coefficient from column (5) of Table 4. Drawing together the above, we find that learning, increased production of overlapping product generations, increased labor, reduction of focus product customizations, and reduction of share of non-focus products yield a proportionate increase in output over the period we study of $(3.41 * 1.43 * 1.52 * 2.2 * 1.03)=16.7$. The factors included in our model thus account for the more than 16-fold increase in output achieved by the firm over the time period of our study.

Our production function estimates also permit answering "what if" questions. For example, what would it save to decrease the proportion of focus product customizations by $1 \%$ ? This can be answered by determining the amount by which labor would be able to be decreased (or saved) as a consequence of decreased customizations when holding constant the number of units produced. From equation (6), we see that this requires holding constant the following: $\beta_{3} \ln \left(L_{t}\right)+\beta_{6} M_{f, t}$. Inserting our estimates from column (5) of Table 4, this implies holding constant $0.259 \ln \left(L_{t}\right)-813.0 M_{f, t}$. Using this result and evaluating at sample averages, we find that a $1 \%$ decrease in customizations would allow decreasing labor inputs by approximately $2.2 \%$. The same analysis for non-focus products reveals that a $1 \%$ decrease in non-focus customizations would enable approximately a $0.9 \%$ decrease (or savings) in labor. The firm would, of course, need to balance the cost savings associated with reduced labor requirements against potential revenue lost from reduced customer-specific product offerings.

\section{Conclusions and Discussion}

The production and operations management literature generally starts from the assumption that producing a variety of products decreases productivity. As a consequence, a significant portion of the literature focuses on developing strategies to counteract the complications of a varied product mix [Womack et al. (1990), Fisher and Ittner (1999), Desai 
et al. (2001), Suarez et al. (1995)]. In contrast, the organizational learning literature provides cases where organizations learn more from diverse than homogenous experiences, where product heterogeneity is beneficial for learning, and where changes in product mix stimulate more efficient resource allocation [Haunschild and Sullivan (2002), Schilling et al. (2003), Bernard et al. (2010), Wiersma (2007)]. Prior to the current paper, the benefits of heterogeneity have not been found in a traditional manufacturing environment.

Drawing on 10 years of production and human resource tracking system data from a manufacturing facility that is a leading producer of high technology hardware components, we demonstrate that whether product heterogeneity is helpful or harmful depends on the extent of the differences between the products on the line. Consistent with the organizational learning literature, we find that productivity improves when multiple generations of the same product are produced at the same time. We were able to investigate a mechanism, knowledge transfer that could explain the benefits of product heterogeneity. The positive impact on productivity of having multiple generations of the same product on the line is explained in part by the firm's ability to transfer knowledge from older to newer generations of the product. We also find that having multiple generations of the focus product on the line is beneficial to firm productivity above and beyond the benefits of generational knowledge transfer.

At the same time, we find productivity is decreased when the production line is faced with products that are very different (e.g., low-volume non-focus products) and when faced with extensive within-product variation (e.g., buyer-specific product customizations). This variety takes a toll on the firm's productivity, in accord with the assumption underlying much of the production and operations management literature.

In addition to enabling us to provide a comprehensive analysis of learning and other factors influencing productivity, the rich dataset that we collected provides us with strong instruments to investigate potential endogeneity. Our measures of product order arrivals provide ideal instruments for the product heterogeneity variables because such order arrivals are the central driver of heterogeneity of products produced, but the timing of order placements is exogenous to the production process at the firm. As we demonstrated, our findings are robust to correction for potential endogeneity bias.

Our study is, of course, limited to one firm. While studying only one firm allows us to focus on a specific multi-product context, gain a deep understanding of the organization, 
and collect a rich dataset, it will be important to test the implications of product heterogeneity on learning and knowledge transfer in additional settings. We expect our results will most likely generalize to other facilities with labor-intensive production of complex products. Interesting additional contexts that would enable us to identify the boundary conditions for our findings include highly automated mechanical assembly factories as well as different industries, such as pharmaceuticals or chemicals [Lieberman (1984)], where production focuses on processes rather than products.

Our findings have important implications for organizations that manage a multitude of products in one location. Our results suggest that industries that see products evolve through generations can benefit - in terms of productivity - from co-producing older products at the same time as newer ones in the same facility. On the other hand, producing distinctly different products, even if only in small volumes, and customizing to meet different buyer specifications, can hurt firm productivity. In addition to building understanding of the mechanisms of learning by doing, our approach can also aid firms in evaluating whether the revenue benefits of offering particular products and customer-specific customizations are sufficient to compensate for the adverse productivity effects of product variety offered. 


\section{Appendix A: Engineer Survey Questions}

\section{Background Information:}

What is your name?

What is your position title at [firm]?

What is your email address and phone extension (will only be used for questions on survey)?

When did you start working at [firm]?

What production area do you work in (example: [stage 1, stage 2], etc.)

What types of products or processes have you worked on during your tenure at [firm]?

Questions on Processes \& Products:

For questions that ask about specific product families, please only fill out information on products that you have worked with directly.

1. In your mind, what makes products similar during production (for example, [end use application], [attribute $(\mathrm{A}$ or $\mathrm{B})]$, products that undergo certain process steps, products that have a specific form factor or component)?

2. Please describe your experience with implementing a new product on the production line. Please be as specific as possible.

3. Please rate each process step for each grouping of products based on difficulty for the line worker on a scale of $1-5$ where 1 is very simple, 2 is simple, 3 is neutral, 4 is difficult, and 5 is very difficult.

\begin{tabular}{|l|l|l|l|l|l|l|l|l|}
\hline Process Step & $\mathbf{1 a}$ & $\mathbf{1 b}$ & $\mathbf{2 a}$ & $\mathbf{2 b}$ & $\mathbf{3 a}$ & $\mathbf{3 b}$ & $\mathbf{4 a}$ & $\mathbf{4 b}$ \\
\hline Process Step 1 & & & & & & & & \\
\hline Process Step 2 & & & & & & & & \\
\hline .. & & & & & & & & \\
\hline Process Step 77 & & & & & & & & \\
\hline
\end{tabular}

4. For your production area, what percentage of machines are used on both products in a given box below? Example for bold box: $\mathrm{x} \%$ of machinery used for 1a products is also used for $1 \mathrm{~b}$ products.

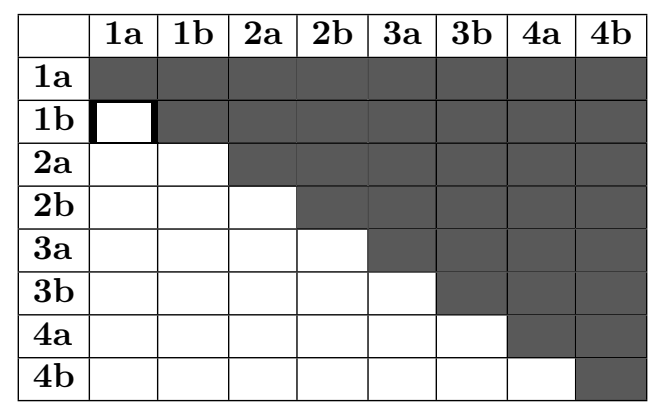

5. For your production area, what percentage of trainers have ever worked on both products in a given box below?

Example for bold box: $\mathrm{x} \%$ of trainers who work on 1a products have also ever worked on $1 \mathrm{~b}$ products. 


\begin{tabular}{|c|c|c|c|c|c|c|c|c|}
\hline & 1a & 1b & 2a & 2b & 3a & 3b & 4a & 4b \\
\hline 1a & & & & & & & & \\
\hline 1b & & & & & & & & \\
\hline 2a & & & & & & & & \\
\hline 2b & & & & & & & & \\
\hline 3a & & & & & & & & \\
\hline 3b & & & & & & & & \\
\hline 4a & & & & & & & & \\
\hline 4b & & & & & & & & \\
\hline
\end{tabular}

6. For your production area, what percentage of technicians have ever worked on both products in a given box below?

Example for bold box: $\mathrm{x} \%$ of technicians who work on 1a products have also ever worked on 1b products.

\begin{tabular}{|l|l|l|l|l|l|l|l|l|}
\hline & $\mathbf{1 a}$ & $\mathbf{1 b}$ & $\mathbf{2 a}$ & $\mathbf{2 b}$ & $\mathbf{3 a}$ & $\mathbf{3 b}$ & $\mathbf{4 a}$ & $\mathbf{4 b}$ \\
\hline 1a & & & & & & & & \\
\hline 1b & & & & & & & & \\
\hline 2a & & & & & & & & \\
\hline 2b & & & & & & & & \\
\hline 3a & & & & & & & & \\
\hline 3b & & & & & & & & \\
\hline 4a & & & & & & & & \\
\hline 4b & & & & & & & & \\
\hline
\end{tabular}

7. What percentage of engineers have ever worked on both products in a given box below?

Example for bold box: $\mathrm{x} \%$ of engineers who work on 1a products have also ever worked on $1 \mathrm{~b}$ products

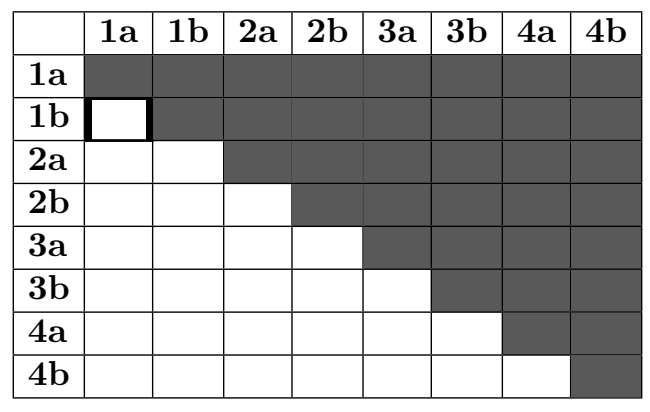

8. For your production area, please list any major tool or equipment changes (if any) that have happened. (For example: new oven, more production lines, new soldering equipment, new automated machinery, etc.) 


\begin{tabular}{|l|l|}
\hline Year & Major tool or equipment changes \\
\hline 2001 & \\
\hline 2002 & \\
\hline 2003 & \\
\hline 2004 & \\
\hline 2005 & \\
\hline 2006 & \\
\hline 2007 & \\
\hline 2008 & \\
\hline 2009 & \\
\hline 2010 & \\
\hline 2011 & \\
\hline
\end{tabular}

\section{Appendix B: Trainer Survey Questions}

Background Information:

What is your name?

What is your position title at [firm]?

What is your email address and phone extension (will only be used for questions on survey)?

When did you start working at [firm]?

What types of products or processes have you worked on during your tenure at [firm]?

Questions on Processes 8 Products:

1. Please describe each type of process (simple, skill-based, criteria-based, special case, hazardous, other) and list how long it takes on average to train a manufacturing specialist in that process.

\begin{tabular}{|l|l|l|l|l|l|l|l|l|}
\hline Process Step & 1a & 1b & 2a & 2b & 3a & 3b & 4a & 4b \\
\hline Process Step 1 & & & & & & & & \\
\hline Process Step 2 & & & & & & & & \\
\hline . & & & & & & & & \\
\hline Process Step 77 & & & & & & & & \\
\hline
\end{tabular}




\section{References}

Alchian, Armen. 1963. Reliability of Progress Curves in Airframe Production. Econometrica: Journal of the Econometric Society 679-693.

Argote, Linda. 2013. Organizational Learning: Creating, Retaining and Transferring Knowledge. 2nd ed. Springer.

Argote, Linda, Sara Beckman, Dennis Epple. 1990. The persistence and transfer of learning in industrial settings. Management Science 36(2) 140-154.

Argote, Linda, Dennis Epple. 1990. Learning curves in manufacturing. Science 247(4945) 920-924.

Argote, Linda, Paul Ingram. 2000. Knowledge Transfer: A Basis for Competitive Advantage in Firms. Organizational Behavior and Human Decision Processes 82(1) 150-169.

Argote, Linda, Bill McEvily, Ray Reagans. 2003. Introduction to the Special Issue on Managing Knowledge in Organizations: Creating, Retaining, and Transferring Knowledge. Management Science 49(4) v-viii.

Benkard, C Lanier. 2000. Learning and Forgetting: The Dynamics of Aircraft Production. The American Economic Review 90(4) 1034-1054.

Bernard, Andrew, Stephen Redding, Peter Schott. 2010. Multiple-Product Firms and Product Switching. American Economic Review 100(1) 70-97.

Boh, Wai Fong, Sandra A Slaughter, J Alberto Espinosa. 2007. Learning from Experience in Software Development: A Multilevel Analysis. Management Science 53(8) 1315-1331.

Darr, Eric, Linda Argote, Dennis Epple. 1995. The acquisition, transfer, and depreciation of knowledge in service organizations: Productivity in franchises. Management Science 41(11) 1750-1762.

David, Guy, Tanguy Brachet. 2011. On the Determinants of Organizational Forgetting. American Economic Journal: Microeconomics 3(3) 100-123.

Desai, Preyas, Sunder Kekre, Suresh Radhakrishnan, Kannan Srinivasan. 2001. Product Differentiation and Commonality in Design: Balancing Revenue and Cost Drivers. Management Science 47(1) 37-51.

Dutton, John, Annie Thomas. 1984. Treating Progress Functions as a Managerial Opportunity. The Academy of Management Review 9(2) 235-247.

Epple, Dennis, Linda Argote, Rukmini Devadas. 1991. Organizational learning curves: A method for investigating intra-plant transfer of knowledge acquired through learning by doing. Organization Science 2(1) 58-70.

Epple, Dennis, Linda Argote, Kenneth Murphy. 1996. An empirical investigation of the microstructure of knowledge acquisition and transfer through learning by doing. Operations Research 44 77-86.

Fisher, Marshall, Christopher Ittner. 1999. The Impact of Product Variety on Automobile Assembly Operations: Empirical Evidence and Simulation Analysis. Management Science 45(6) 771-786. 
Fisher, Marshall, Kamalini Ramdas, Karl Ulrich. 1999. Component Sharing in the Management of Product Variety: A Study of Automotive Braking Systems. Management Science 45(3) 297-315.

Gaimon, Cheryl, Alysse Morton. 2005. Investment in Facility Changeover Flexibility for Early Entry into High-Tech Markets. Production and Operations Management 14(2) 159-174.

Gopal, A, M Goyal, S Netessine, M Reindorp. 2013. The Impact of New Product Introduction on Plant Productivity in the North American Automotive Industry. Management Science .

Goyal, M, S Netessine. 2011. Volume Flexibility, Product Flexibility, or Both: The Role of Demand Correlation and Product Substitution. Manufacturing \& Service Operations Management 13(2) 180-193.

Greene, William H. 2003. Econometric Analysis. 5th ed. Prentice Hall.

Hall, Bronwyn. 2005. Note on the Bias in the Herfindahl Based on Count Data. Revue d'Economie Industrielle $110149-156$.

Haunschild, Pamela, Bilian Sullivan. 2002. Learning from Complexity: Effects of Prior Accidents and Incidents on Airlines' Learning. Administrative Science Quarterly 47(4) 609-643.

Ingram, Paul, Tal Simons. 2002. The Transfer of Experience in Groups of Organizations: Implications for Performance and Competition. Management Science 48(12) 1517-1533.

Irwin, Douglas, Peter Klenow. 1994. Learning-by-Doing Spillovers in the Semiconductor Industry. The Journal of Political Economy 102(6) 1200-1227.

Kekre, Sunder, Kannan Srinivasan. 1990. Broader Product Line: A Necessity to Achieve Success? Management Science 36(10) 1216-1231.

Kellogg, R. 2011. Learning by Drilling: Interfirm Learning and Relationship Persistence in the Texas Oilpatch. The Quarterly Journal of Economics 126(4) 1961-2004.

Kim, Ilhyung, Hae Lim Seo. 2009. Depreciation and transfer of knowledge: an empirical exploration of a shipbuilding process. International Journal of Production Research 47(7) 1857-1876.

Kogut, Bruce, Udo Zander. 1992. Knowledge of the Firm, Combinative Capabilities, and the Replication of Technology. Organization Science 3(3) 383-397.

Lapré, Michael A, Amit Shankar Mukherjee, Luk N Van Wassenhove. 2000. Behind the Learning Curve: Linking Learning Activities to Waste Reduction. Management Science 46(5) 597-611.

Lapré, Michael A, Ingrid M Nembhard. 2010. Inside the Organizational Learning Curve: Understanding the Organizational Learning Process. Foundations and Trends® in Technology, Information and Operations Management 4(1) 1-103.

Levitt, Steven D, John A List, Chad Syverson. 2013. Toward an Understanding of Learning by Doing: Evidence from an Automobile Assembly Plant. Journal of Political Economy 121(4) 643-681.

Lieberman, Marvin B. 1984. The Learning Curve and Pricing in the Chemical Processing Industries. The RAND Journal of Economics 15(2) 213-228. 
MacDuffie, John, Kannan Sethuraman, Marshall Fisher. 1996. Product Variety and Manufacturing Performance: Evidence from the International Automotive Assembly Plant Study. Management Science 42(3) 350-369.

Madsen, P M, V Desai. 2010. Failing to Learn? The Effects of Failure and Success on Organizational Learning in the Global Orbital Launch Vehicle Industry. Academy of Management Journal 53(3) 451-476.

Palan, Nicole. 2010. Measurement of Specialization - The Choice of Indices. FIW Working Paper 1-38.

Randall, Taylor, Karl Ulrich. 2001. Product Variety, Supply Chain Structure, and Firm Performance: Analysis of the U. S. Bicycle Industry. Management Science 47(12) 1588-1604.

Rapping, Leonard. 1965. Learning and World War II Production Functions. The Review of Economics and Statistics 47(1) 81-86.

Schilling, Melissa A, Patricia Vidal, Robert E Ployhart, Alexandre Marangoni. 2003. Learning by Doing Something Else: Variation, Relatedness, and the Learning Curve. Management Science 49(1) 39-56.

Shtub, Avraham, Nissan Levin, Shlomo Globerson. 1993. Learning and forgetting industrial skills: An experimental model. International Journal of Human Factors in Manufacturing 3(3) 293-305.

Smith, Adam. 1776. The Wealth of Nations. University of Chicago Press, Chichago, IL.

Staats, Bradley, Francesca Gino. 2011. Specialization and Variety in Repetitive Tasks: Evidence from a Japanese Bank. Working Paper 1-33.

Suarez, Fernando, Michael Cusumano, Charles Fine. 1995. An Empirical Study of Flexibility in Manufacturing. Sloan Management Review 37(1) 25-32.

Suarez, Fernando, Michael Cusumano, Charles Fine. 1996. An Empirical Study of Manufacturing Flexibility in Printed Circuit Board Assembly. Operations Research 44(1) 223-240.

Thompson, Peter. 2007. How Much Did the Liberty Shipbuilders Forget? Management Science 53(6) 908-918.

Ton, Zeynep, Robert S Huckman. 2008. Managing the Impact of Employee Turnover on Performance: The Role of Process Conformance. Organization Science 19(1) 56-68.

Walsh, James P, Gerado Rivera Ungson. 1991. Organizational Memory. Academy of Management Review 16(1) $57-91$.

Wiersma, Eelke. 2007. Conditions That Shape the Learning Curve: Factors That Increase the Ability and Opportunity to Learn. Management Science 53(12) 1903-1915.

Womack, James P, Daniel T Jones, Daniel Roos. 1990. The Machine That Changed the World: The Story of Lean Production. 1st ed. Harper Perennial, New York. 